\title{
Temperature Dependent Electrical Transport in Al/Poly(4-vinyl phenol)/p-GaAs Metal-Oxide-Semiconductor by Sol-Gel Spin Coating Method
}

\author{
Şadan Özden, ${ }^{1}$ Cem Tozlu, ${ }^{2}$ and Osman Pakma ${ }^{3}$ \\ ${ }^{1}$ Department of Physics, Faculty of Sciences, Muğla Sıtkı Koçman University, 48170 Muğla, Turkey \\ ${ }^{2}$ Department of Energy Engineering, Faculty of Engineering, Karamanoğlu Mehmetbey University, 70100 Karaman, Turkey \\ ${ }^{3}$ Department of Physics, Faculty of Arts and Sciences, Batman University, 72000 Batman, Turkey \\ Correspondence should be addressed to Şadan Özden; sadanozden@gmail.com
}

Received 6 January 2016; Accepted 24 February 2016

Academic Editor: Mahmoud M. El-Nahass

Copyright (C) 2016 Şadan Özden et al. This is an open access article distributed under the Creative Commons Attribution License, which permits unrestricted use, distribution, and reproduction in any medium, provided the original work is properly cited.

Deposition of poly(4-vinyl phenol) insulator layer is carried out by applying the spin coating technique onto $p$-type GaAs substrate so as to create $\mathrm{Al} /$ poly(4-vinyl phenol)/p-GaAs metal-oxide-semiconductor (MOS) structure. Temperature was set to $80-320 \mathrm{~K}$ while the current-voltage $(I-V)$ characteristics of the structure were examined in the study. Ideality factor $(n)$ and barrier height $\left(\phi_{b}\right)$ values found in the experiment ranged from 3.13 and $0.616 \mathrm{eV}(320 \mathrm{~K})$ to 11.56 and $0.147 \mathrm{eV}(80 \mathrm{~K})$. Comparing the thermionic field emission theory and thermionic emission theory, the temperature dependent ideality factor behavior displayed that thermionic field emission theory is more valid than the latter. The calculated tunneling energy was $96 \mathrm{meV}$.

\section{Introduction}

Compound semiconductor materials can be used in such applications to achieve better results. Currently, many different compound semiconductors are available, but, among them, gallium arsenide (GaAs) has been the most studied one since the technologies used to process and fabricate this material have been highly developed [1-4]. Due to its direct energy bandgap, GaAs is ideally preferred for light emission and photovoltaic devices. It also has a wide bandgap $(1.5 \mathrm{eV})$ and high electron mobility $\left(8000 \mathrm{~cm}^{2} \mathrm{~V}^{-1} \mathrm{~s}^{-1}\right)$, which has specific advantages in operations requiring high frequency and temperature [5].

The interest in and the efforts toward developing new organic-based electronic and optoelectronic devices have recently increased. Charge carrier injection from electrodes into organic material constitutes one important factor to determine the device function and performance for metalsemiconductor (MS) devices [6]. Modification of the electrical properties of (MS) Schottky structures can be achieved by using an organic semiconductor. In this technique, an organic interfacial layer is inserted between inorganic semiconductor and metal. As they can be applied to various areas like solar cells and Schottky diodes, there has been a growing interest in polymers such as poly(4-vinyl phenol), polyaniline, polyvinyl alcohol (PVA), poly(alkylthiophene) polypyrrole, polythiophene, and poly(3-hexylthiophene) [7-18]. In polymers, we find local free-volume holes or cavities of atomic and molecular dimensions, which may be the result of irregular packing of the molecules in amorphous phase (static and preexisting holes) and molecular relaxation of polymer chains and terminal ends (dynamic and transient holes). The density of the amorphous phase declines due to these holes approximately by $10 \%$, when compared to that of the crystalline phase of the same polymeric material. Thus, such free-volume holes found in a polymeric system influence the polymer's optic, thermal, dielectric, electrical, and relaxing properties. For this reason, poly(4-vinyl phenol) is much more preferred as an insulating layer since it has several advantages such as higher device performance, stability, and reliability over other kinds of insulator layers. Therefore, the use of poly(4-vinyl phenol) as a gate insulator material in 
organic field effect transistors (OFETs) has been common $[18,19]$. The high performance and reliability of OFETs mainly stem from the insulator layer between metal and semiconductor, as well as from the interface states between semiconductor and insulator and series resistance. Poly(4vinyl phenol) has been reported to be the best polymeric gate dielectric in terms of mobility [15]. Device performance is significantly affected by gate dielectric, which is an important component of organic thin film transistors (OTFT) [19]. Yet, certain electrical instabilities are found in an OTFT with poly(4-vinyl phenol) used as the gate dielectric, a case which could be exemplified by bias stress effect or hysteresis, leading to shifting threshold voltage depending on the amount of hydroxyl groups and thus to gate leakage current. The reason behind the occurrence of hysteresis is slow polarization as a result of remnant dipoles and charge injection as well as trapping mechanism [20, 21]. Several experimental studies have been carried out to examine the effect of organic materials used as an insulating layer in device applications $[22,23]$.

In the present study, the current-applied bias voltagetemperature $(I-V-T)$ measurement in darkness was performed to clarify the current transport mechanism(s) and electrical features of $\mathrm{Al} / \mathrm{poly}$ (4-vinyl phenol)/p-GaAs structures.

\section{Design and Fabrication of Al/Poly(4-vinyl phenol)/p-GaAs Structures}

A lot of $\mathrm{Al} /$ poly(4-vinyl phenol)/p-GaAs structures were fabricated on the 2-inch diameter float zone $<111>p$-type (zinc-doped) GaAs wafer with a thickness of $500 \mu \mathrm{m}$ and a resistivity of $2 \Omega \mathrm{cm}$. For the fabrication process, GaAs wafer was degreased through the RCA cleaning procedure. The RCA cleaning procedure has three major steps that are used sequentially: (I) organic cleaning: removal of insoluble organic contaminants with a 10-minute boiling in $\mathrm{NH}_{4} \mathrm{OH}+$ $\mathrm{H}_{2} \mathrm{O}_{2}+6 \mathrm{H}_{2} \mathrm{O}$ solution, (II) oxide stripping: removal of a thin oxide layer where metallic contaminants might have accumulated as a result of (I), using a diluted (30 s) $\mathrm{HF}: \mathrm{H}_{2} \mathrm{O}$ $(1: 10)$ solution, and (III) ionic cleaning: the procedure was followed by a 10 -minute boiling in $\mathrm{HCl}+\mathrm{H}_{2} \mathrm{O}_{2}+$ $6 \mathrm{H}_{2} \mathrm{O}$ solution $[24,25]$. Next, drying was performed in $\mathrm{N}_{2}$ atmosphere for a prolonged time. Following the drying process, In-Ag $(25 \%, 75 \%)$ with a thickness of $2000 \AA$ A was thermally evaporated from the tungsten filament onto the whole back surface of the GaAs wafer under the pressure of $10^{-6}$ Torr. In order to obtain a low-resistivity ohmic back contact, GaAs wafer was sintered at $580^{\circ} \mathrm{C}$ for $3 \mathrm{~min}$ in $\mathrm{N}_{2}$ atmosphere. The poly(4-vinyl phenol) was purchased from Sigma-Aldrich (Sigma-Aldrich Cat. number 436216) with a molecular weight of 20.000. Spin coating process was applied to cover poly (4-vinyl phenol) on the front surface of the GaAs wafer from $2.5 \%$ solution in 2-propanol at $4.000 \mathrm{rpm}$ for $45 \mathrm{~s}$. The obtained film was cross-linked at $100^{\circ} \mathrm{C}$ under vacuum. In order to obtain a rectifying contact on the front surface of p-GaAs coated with poly(4-vinyl phenol) (Figure 1), a highpurity aluminum layer was coated on the surface in a high

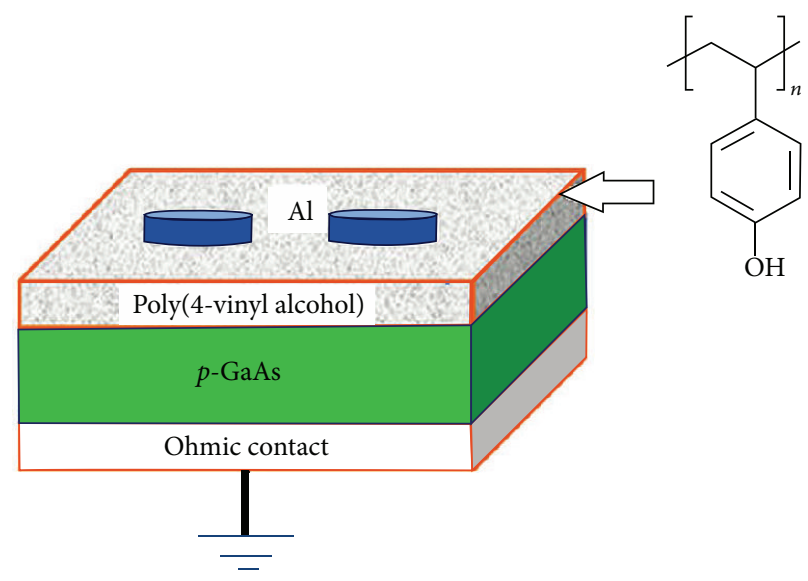

FIGURE 1: Schematic diagram of the Al/poly(4-vinyl phenol)/p-GaAs structure.

vacuum under the pressure of $10^{-7}$ Torr. The interfacial oxide layer thickness was estimated to be about $37 \mathrm{~nm}$ by Avantes spectrometer (AvaSpec-ULS2048).

The current-voltage $(I-V)$ characteristics of the samples were measured in the temperature range of $80-320 \mathrm{~K}$ using a temperature controlled ARS CS202* I-DMX-1SS high performance closed cycle cryostat, which allowed us to perform the measurements in the temperature range of $10-325 \mathrm{~K}$, and using a Keithley 4200 programmable constant current source under dark conditions. The sample temperature was continually monitored using a GaAlAs sensor and a Lakeshore 330 autotuning temperature controller with a sensitivity better than $\pm 0.1 \mathrm{~K}$.

\section{Measurement and Experimental Results}

The current transport across a Schottky junction draws intense interest from both material physicists and device physicist. Usually, a wide range of temperatures are used in determining the Schottky barrier diode (SBD) parameters with the aim of acquiring a better understanding concerning the nature of the barrier and the conduction mechanism. Although, under normal conditions, SBD parameters are obtained through the use of thermionic emission (TE) theory, certain anomalies have been reported at lower temperatures resulting from this theory. The current through a SBD at a forward bias voltage $(V \geq 3 k T / q)$ based on the TE theory is expressed as [26]

$$
I=I_{0}\left[\exp \left(\frac{q V}{n k T}\right)-1\right]
$$

where $I_{0}$ is the reverse saturation current and is described as

$$
I_{0}=A A^{*} T^{2} \exp \left(\frac{-q \phi_{b}}{k T}\right),
$$

where $A, A^{*}, T, k, q$, and $\phi_{b}$ are the rectifier contact area, the effective Richardson constant $\left(74 \mathrm{~A} / \mathrm{cm}^{2} \mathrm{~K}^{2}\right.$ for $p$-type GaAs), the temperature in Kelvin, the Boltzmann constant, the electron charge, and the barrier height, respectively. 
TABLE 1: The $T, n, I_{0}$, and $\phi_{b}$ values for the investigated device structure of Figure 1.

\begin{tabular}{lccc}
\hline$T(\mathrm{~K})$ & $n$ & $I_{0}(\mathrm{~A})$ & $\phi_{b}(\mathrm{eV})$ \\
\hline 80 & 11.56 & $1.83 \times 10^{-06}$ & 0.147 \\
110 & 10.87 & $3.34 \times 10^{-06}$ & 0.203 \\
140 & 8.76 & $4.29 \times 10^{-06}$ & 0.262 \\
170 & 6.54 & $5.90 \times 10^{-06}$ & 0.319 \\
200 & 5.32 & $6.59 \times 10^{-06}$ & 0.379 \\
230 & 4.12 & $7.28 \times 10^{-06}$ & 0.439 \\
260 & 3.43 & $8.29 \times 10^{-06}$ & 0.499 \\
290 & 3.23 & $9.73 \times 10^{-06}$ & 0.558 \\
320 & 3.13 & $1.17 \times 10^{-05}$ & 0.616 \\
\hline
\end{tabular}

The ideality values are derived from the slope of the linear region of the forward bias $\ln I-V$ plots and can be calculated from (1) as

$$
n=\frac{q}{k T} \frac{d V}{d(\ln I)}
$$

In Figure 2, a typical temperature dependence is displayed in semilogarithmic plots of $I-V$ characteristics of $\mathrm{Al} /$ poly $(4-$ vinyl phenol) $/ p$-GaAs structure under higher voltages. The $I-$ $V$ plots shift toward the side with higher bias, but a decrease is observed in temperature. As can be seen in Figure 2, the forward bias $I-V$ characteristics lose a significant amount of their linearity because of the series resistance effect of the Al/poly(4-vinyl phenol)/p-GaAs structure in high voltage region. The experimental values of $n$ and $\phi_{b}$ by using linear parts of the $I-V$ characteristics were calculated through (2) and (3), respectively. Besides, $n$ and $\phi_{b}$ values of each temperature are displayed in Table 1 . As it is obvious in Figure 3, these two parameters have a strong temperature dependency. Figure 3 reveals that $n$ values increased while $\phi_{b}$ values decreased together with a decreasing temperature. The current transport will be dominated by the current flowing through the lower $\mathrm{BH}$ and a larger ideality factor due to the temperature activated process [27]. In other words, a higher number of electrons have sufficient energy to overcome the higher barrier when temperature increases and, in turn, $\mathrm{BH}$ is increased by temperature and bias voltage.

The conventional Richardson plot of $\ln \left(I_{0} / T^{2}\right)$ versus $1 / k T$ was obtained and is shown in Figure 4. The values of activation energy and Richardson constant were obtained from the slope of this straight line as $0.0178 \mathrm{eV}$ and $2.71 \times$ $10^{-3} \mathrm{~A} / \mathrm{cm}^{2} \mathrm{~K}^{2}$, respectively. The Richardson constant value of $2.71 \times 10^{-3} \mathrm{~A} / \mathrm{cm}^{2} \mathrm{~K}^{2}$ is much lower than the known value of $74 \mathrm{~A} / \mathrm{cm}^{2} \mathrm{~K}^{2}$ for $p$-type GaAs. As explained above, the deviation in the Richardson plots might be a result of the spatially inhomogeneous $\mathrm{BHs}$ and potential fluctuations at the interface, which consist of low and high barrier areas [28-33]; in other words, the current through the barrier will flow preferentially through the lower barriers in the potential distributions.

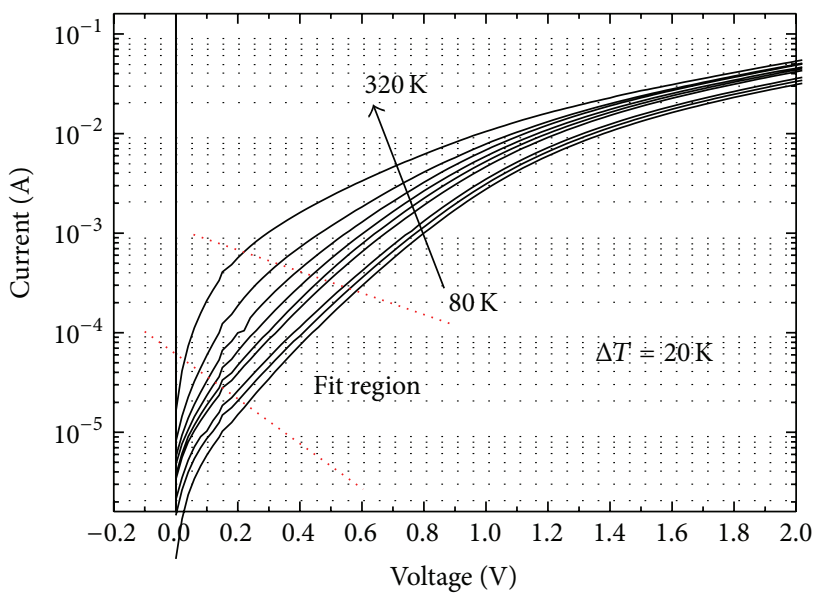

Figure 2: Experimental forward bias $\ln I-V$ characteristics of the $\mathrm{Al} /$ poly(4-vinyl phenol)/p-GaAs structure at various temperatures.

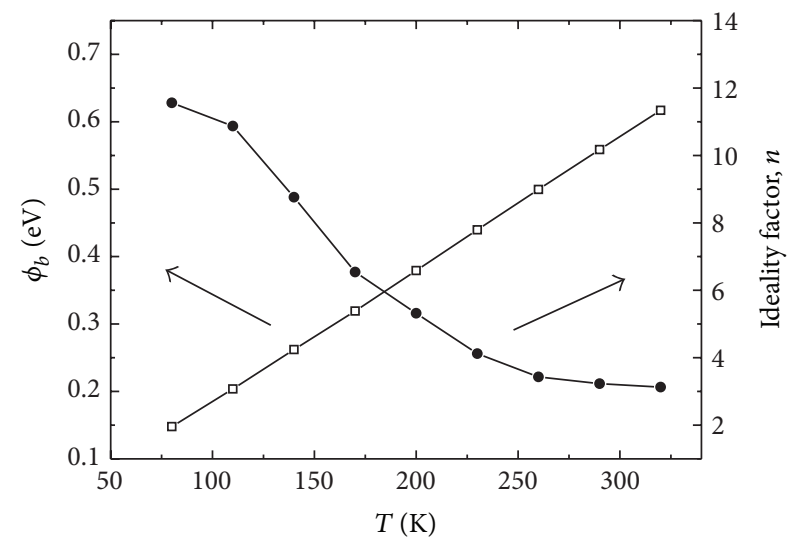

FIgURE 3: Temperature dependencies of experimental $\phi_{b}$ and $n$ values obtained from current versus voltage characteristics of $\mathrm{Al} /$ poly(4-vinyl phenol)/p-GaAs structure between 80 and $320 \mathrm{~K}$.

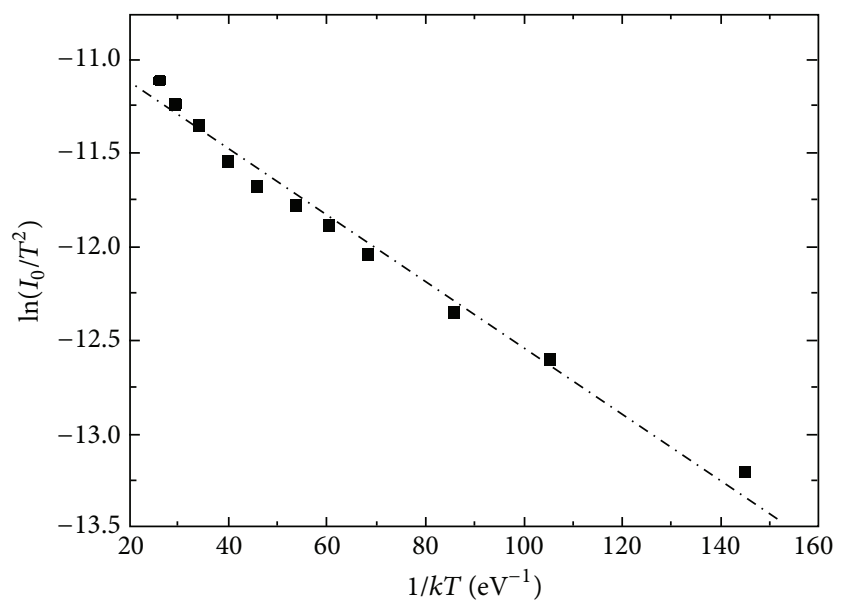

FIgURE 4: The conventional Richardson plot of $\ln \left(I_{0} / T^{2}\right)$ versus $1 / k T$ of $\mathrm{Al} /$ poly (4-vinyl phenol)/p-GaAs structure. 
The high ideality factor value (greater than unity) and its temperature dependence assume that the principally dominant factor of the current is the thermionic field emission (TFE). When the TFE theory suggested by Padovani $[34,35]$ is used to control the current transport, the relationship emerging between the current and voltage can be expressed with the following equation [26]:

$$
I=I_{0} \exp \left(\frac{q V}{E_{0}}\right)
$$

with

$$
E_{0}=E_{00} \operatorname{coth}\left(\frac{E_{00}}{k T}\right)=n_{\mathrm{tun}} k T
$$

where $E_{00}$ is the characteristic tunneling energy that is related to the tunnel effect transmission probability:

$$
E_{00}=\frac{h}{4 \pi}\left(\frac{N_{A}}{m^{*} \varepsilon_{s}}\right)^{1 / 2}
$$

where $N_{A}=1.3 \times 10^{19} \mathrm{~cm}^{-3}, \mathrm{~m}^{*}=0.6 m_{0}=0.0402$, and $\varepsilon_{s}=$ $12.9 \varepsilon_{0}$ for $p$-type GaAs and $h=6.626 \times 10^{-34} \mathrm{Js}$. The value of $E_{00} / k T$ at room temperature was found to be 5.66. However, the experimental value of $E_{00} / k T$ at room temperature was determined as 3.71. If $E_{00}>k T$, tunneling dominates since the Boltzmann distribution tail of thermionic emission reduces by a factor of $\exp \{-1\}$ every $k T$ and it is much faster when compared to the decrease rate of the tunneling probability [36]. On the other hand, thermionic emission dominates whenever $E_{00} \ll k T$ because the tunneling probability drops faster than thermionic emission in such a situation. In empirical and practical terms, it is observed that the effect caused by tunneling is small at room temperature for common semiconductors having a doping level of $1 \times$ $10^{17} \mathrm{~cm}^{-3}$ or less $\left(E_{00} \sim 3 \mathrm{meV}\right)$, but it will be pretty significant for semiconductors with a doping level higher than $1 \times$ $10^{18} \mathrm{~cm}^{-3}\left(E_{00} \sim 10 \mathrm{meV}\right)$. In our study, as the doping level is $1.3 \times 10^{19} \mathrm{~cm}^{-3}$, tunneling energy is found as $96 \mathrm{meV}$ in our calculations as can be seen in Figure 5.

\section{Conclusions}

Measurements of the forward bias $I-V$ characteristics of the $\mathrm{Al} /$ poly(4-vinyl phenol)/p-GaAs metal-oxide-semiconductor (MOS) structure were carried out in a temperature range of $80-320 \mathrm{~K}$. Experimental forward bias $I-V$ characteristics were analyzed and an increase was observed in barrier height as well as a decrease in the ideality factor with an increasing temperature. Comparing the thermionic field emission theory and thermionic emission theory, the temperature dependent ideality factor behavior displays that thermionic field emission theory is more valid than the latter. The calculated tunneling energy was $96 \mathrm{meV}$.

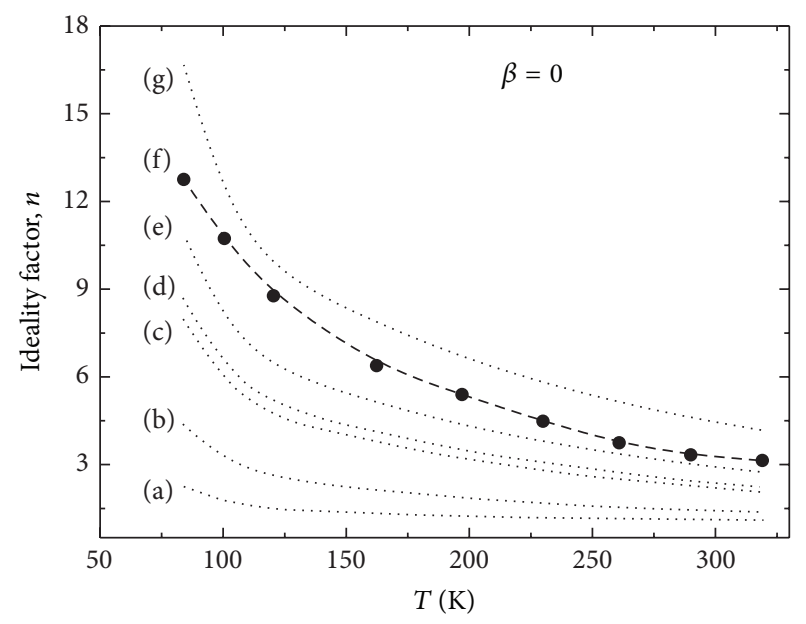
(a) $E_{00}=5 \mathrm{meV}$
(b) $E_{00}=30 \mathrm{meV}$
(e) $E_{00}=75 \mathrm{meV}$
(c) $E_{00}=45 \mathrm{meV}$
(d) $E_{00}=60 \mathrm{meV}$
(f) $E_{00}=96 \mathrm{meV}$
(g) $E_{00}=115 \mathrm{meV}$

FIgURE 5: Thermionic field emission (TFE) fits obtained by fitting (6) to the temperature dependence values of experimental ideality factors calculated for different values of the characteristic energy $E_{00}$, without considering the bias coefficient of the barrier height, $\beta=$ 0 , for $\mathrm{Al} / \mathrm{poly}$ (4-vinyl phenol)/p-GaAs structure. The filled circles show the temperature dependence values of experimental ideality factor obtained from the $I-V$ characteristics.

\section{Competing Interests}

The authors declare that there are no competing interests regarding the publication of this paper.

\section{References}

[1] C. C. Lee, W. V. Chen, and J. Park, "A new I-V model for lightemitting devices with a quantum well," Microelectronics Journal, vol. 37, no. 11, pp. 1335-1338, 2006.

[2] S. Kim, D.-M. Geum, M.-S. Park, C. Z. Kim, and W. J. Choi, "GaAs solar cell on Si substrate with good ohmic GaAs/Si interface by direct wafer bonding," Solar Energy Materials and Solar Cells, vol. 141, pp. 372-376, 2015.

[3] C.-H. Chen, S. M. Baier, D. K. Arch, and M. S. Shur, "A new and simple model for GaAs heterojunction FET characteristics," IEEE Transactions on Electron Devices, vol. 35, no. 5, pp. 570$577,1988$.

[4] R.-H. Horng, M.-C. Tseng, and S.-Y. Lien, "Reliability analysis of III-V solar cells grown on recycled GaAs substrates and an electroplated nickel substrate," International Journal of Photoenergy, vol. 2013, Article ID 108696, 9 pages, 2013.

[5] A. Dargys and J. Kundrotas, Handbook on Physical Properties of Ge, Si, GaAs and InP, Science and Encyclopedia, Vilnius, Lithuania, 1994.

[6] N. Koch, A. Kahn, J. Ghijsen et al., "Conjugated organic molecules on metal versus polymer electrodes: demonstration of a key energy level alignment mechanism," Applied Physics Letters, vol. 82, no. 1, pp. 70-72, 2003.

[7] A. A. M. Farag, E. A. A. El-Shazly, M. Abdel Rafea, and A. Ibrahim, "Optical, electrical and photovoltaic characteristics of 
organic semiconductor based on oxazine/n-Si heterojunction," Solar Energy Materials and Solar Cells, vol. 93, no. 10, pp. 18531859, 2009.

[8] M. E. Aydin and F. Yakuphanoglu, "Electrical and interface state density properties of the $4 \mathrm{H}-\mathrm{nSiC} /[6,6]$-phenyl C61-butyric acid methyl ester/Au diode," Microelectronic Engineering, vol. 85, no. 8, pp. 1836-1841, 2008.

[9] O. Pakma, C. Tozlu, N. Kavasoglu, A. S. Kavasoglu, and S. Ozden, "I-V-T analyzing an inhomogeneous Au/Poly(4-vinyl phenol)/p-Si structure with a double Gaussian distribution of barrier heights," Journal of Sol-Gel Science and Technology, vol. 58, pp. 244-250, 2011.

[10] F. Yakuphanoglu and S. Okur, "Analysis of electronic parameters and interface states of boron dispersed triethanolamine/pSi structure by AFM, I-V, C-V-f and G/ $\omega$-V-f techniques," Microelectronic Engineering, vol. 87, no. 1, pp. 30-34, 2010.

[11] Ö. Güllü, "Impedance and interface properties of Al/Methyl$\mathrm{Red} / \mathrm{p}$-InP solar cell," International Journal of Photoenergy, vol. 2009, Article ID 374301, 7 pages, 2009.

[12] R. Şahingöz, H. Kanbur, M. Voigt, and C. Soykan, "The determination of interface states and series resistance profile of Al/polymer/PEDOT-PSS/ITO heterojunction diode by I-V and C-V methods," Synthetic Metals, vol. 158, pp. 727-731, 2008.

[13] A. S. Kavasoglu, C. Tozlu, O. Pakma et al., "Investigation of temperature dependent dc current transport mechanism on Au/poly(4-vinyl phenol)/p-Si device," Journal of Physics D: Applied Physics, vol. 42, no. 14, Article ID 145111, 6 pages, 2009.

[14] S. Altindal, B. Sari, H. I. Unal, and N. Yavas, "Electrical characteristics of Al/polyindole Schottky barrier diodes. I. Temperature dependence," Journal of Applied Polymer Science, vol. 113, no. 5, pp. 2955-2961, 2009.

[15] A. F. Özdemir, D. A. Aldemir, A. Kökce, and S. Altindal, "Electrical properties of $\mathrm{Al} /$ conducting polymer $(\mathrm{P} 2 \mathrm{ClAn}) / \mathrm{p}$ Si/Al contacts," Synthetic Metals, vol. 159, no. 14, pp. 1427-1432, 2009.

[16] İ. Dökme, Ş. Altindal, T. Tunç, and İ. Uslu, “Temperature dependent electrical and dielectric properties of Au/polyvinyl alcohol (Ni, Zn-doped)/n-Si Schottky diodes," Microelectronics Reliability, vol. 50, no. 1, pp. 39-44, 2010.

[17] C. Joachim, J. K. Gimzewski, and A. Aviram, "Electronics using hybrid-molecular and mono-molecular devices," Nature, vol. 408, no. 6812, pp. 541-548, 2000.

[18] S. H. Kim, J. Jang, H. Jeon, W. M. Yun, S. Nam, and C. E. Park, "Hysteresis-free pentacene field-effect transistors and inverters containing poly(4-vinyl phenol-co-methyl methacrylate) gate dielectrics," Applied Physics Letters, vol. 92, no. 18, Article ID 183306, 2008.

[19] C. A. Lee, D. W. Park, K. D. Jung et al., "Hysteresis mechanism in pentacene thin-film transistors with poly (4-vinyl phenol) gate insulator," Applied Physics Letters, vol. 89, no. 26, Article ID 262120, 2006.

[20] S.-J. Choi, J.-H. Kim, and H. H. Lee, "Deep-UV curing of poly(4-vinyl phenol) gate dielectric for hysteresis-free organic thin-film transistors," IEEE Electron Device Letters, vol. 30, no. 5, pp. 454-456, 2009.

[21] K.-H. Lee, B. J. Park, H. J. Choi, J. Park, and J. S. Choi, “Effect of surfactant on preparation of poly(4-vinylphenol)/titanium dioxide composite for a gate insulator of organic thin film transistors," Molecular Crystals and Liquid Crystals, vol. 471, no. 1, pp. 173-179, 2007.

[22] F. Yakuphanoglu, "Electrical conductivity, optical and metalsemiconductor contact properties of organic semiconductor based on MEH-PPV/fullerene blend," Journal of Physics and Chemistry of Solids, vol. 69, no. 4, pp. 949-954, 2008.

[23] Ö. Güllü, Ş. Aydoan, and A. Türüt, "Fabrication and electrical properties of Al/Safranin T/n-Si/AuSb structure," Semiconductor Science and Technology, vol. 23, no. 7, Article ID 075005, 2008.

[24] W. Kern, Handbook of Semiconductor Cleaning Technology, Noyes, New York, NY, USA, 1993.

[25] O. Pakma, "Current mechanism in $\mathrm{HfO}_{2}$-gated metal-oxidesemiconductor devices," International Journal of Photoenergy, vol. 2012, Article ID 858350, 7 pages, 2012.

[26] E. H. Rhoderick and R. H. Williams, Metal-Semiconductor Contacts, Clarendon Press, Oxford, UK, 1978.

[27] R. F. Schmitsdorf, T. U. Kampen, and W. Mönch, "Explanation of the linear correlation between barrier heights and ideality factors of real metal-semiconductor contacts by laterally nonuniform Schottky barriers," Journal of Vacuum Science and Technology B: Microelectronics and Nanometer Structures, vol. 15, no. 4, pp. 1221-1226, 1997.

[28] S. Duman, B. Gurbulak, and A. Türüt, “Temperature-dependent optical absorption measurements and Schottky contact behavior in layered semiconductor n-type InSe(:Sn)," Applied Surface Science, vol. 253, no. 8, pp. 3899-3905, 2007.

[29] E. Dobročka and J. Osvald, "Influence of barrier height distribution on the parameters of Schottky diodes," Applied Physics Letters, vol. 65, no. 5, pp. 575-577, 1994.

[30] F. E. Jones, B. P. Wood, J. A. Myers, C. Daniels-Hafer, and M. C. Lonergan, "Current transport and the role of barrier inhomogeneities at the high barrier n-InP - poly(pyrrole) interface," Journal of Applied Physics, vol. 86, no. 11, pp. 64316441, 1999.

[31] M. C. Lonergan and F. E. Jones, "Calculation of transmission coefficients at nonideal semiconductor interfaces characterized by a spatial distribution of barrier heights," Journal of Chemical Physics, vol. 115, no. 1, pp. 433-445, 2001.

[32] A. Gümüş, A. Türüt, and N. Yalçın, “Temperature dependent barrier characteristics of CrNiCo alloy Schottky contacts on ntype molecular-beam epitaxy GaAs," Journal of Applied Physics, vol. 91, no. 1, pp. 245-250, 2002.

[33] H. Von Wenckstern, G. Biehne, R. A. Rahman, H. Hochmuth, M. Lorenz, and M. Grundmann, "Mean barrier height of Pd Schottky contacts on $\mathrm{ZnO}$ thin films," Applied Physics Letters, vol. 88, no. 9, Article ID 092102, 2006.

[34] F. A. Padovani and G. G. Sumner, "Experimental study of goldgallium arsenide Schottky barriers," Journal of Applied Physics, vol. 36, no. 12, pp. 3744-3747, 1965.

[35] F. A. Padovani and R. Stratton, "Field and thermionic-field emission in Schottky barriers," Solid State Electronics, vol. 9, no. 7, pp. 695-707, 1966.

[36] R. T. Tung, "Electron transport at metal-semiconductor interfaces: general theory," Physical Review B, vol. 45, no. 23, pp. 13509-13523, 1992. 

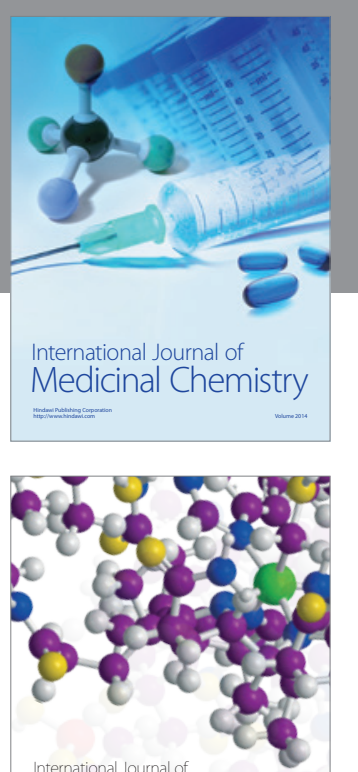

Carbohydrate Chemistry

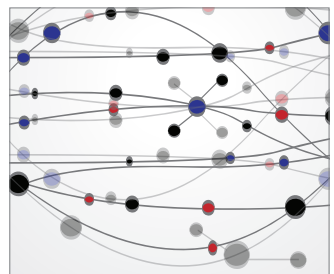

The Scientific World Journal
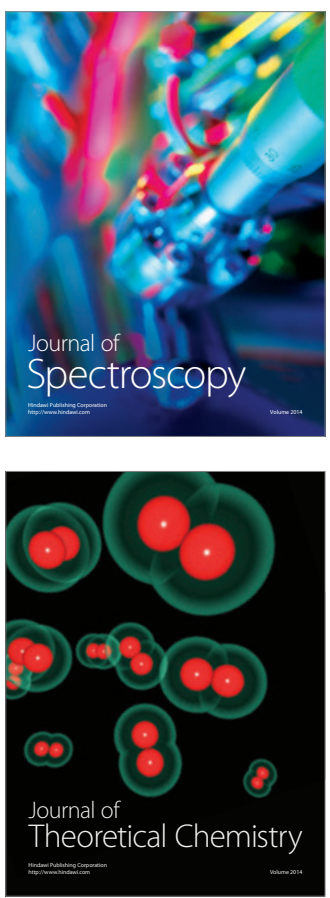
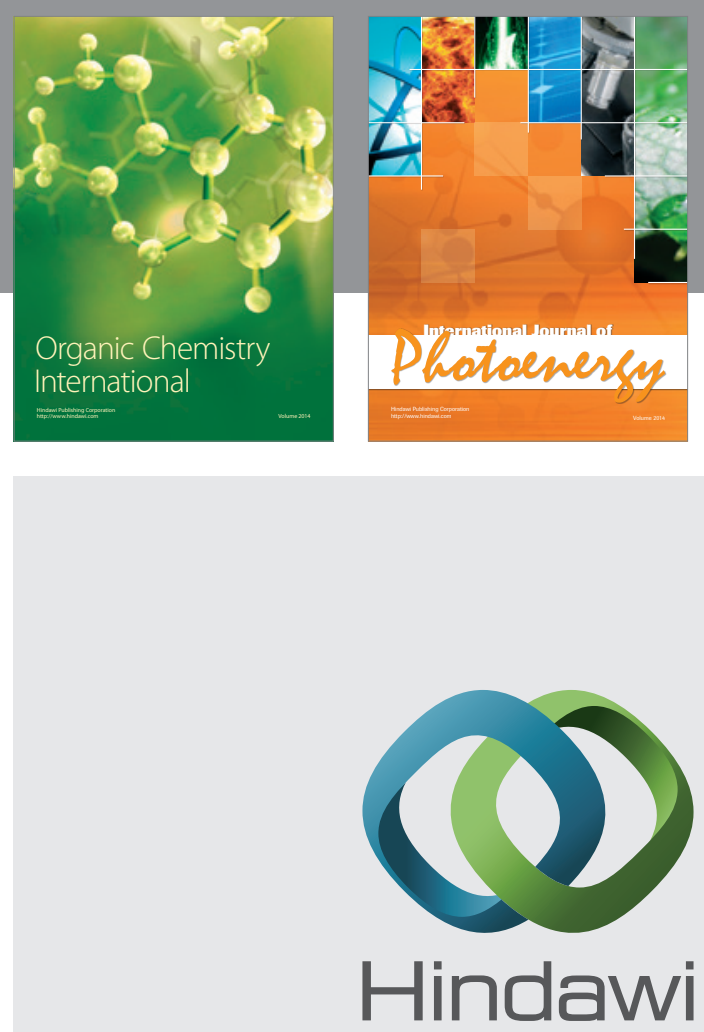

Submit your manuscripts at

http://www.hindawi.com

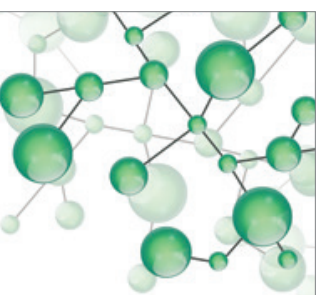

International Journal of

Inorganic Chemistry

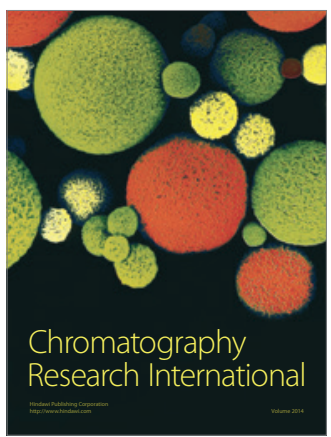

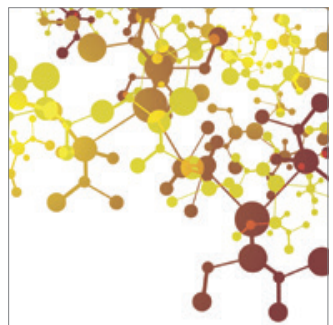

Applied Chemistry
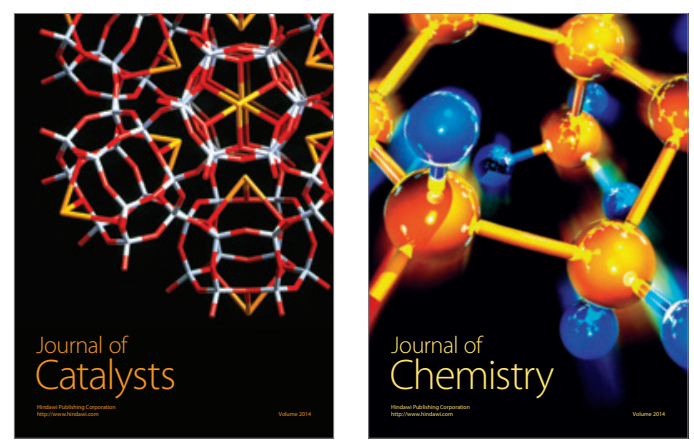
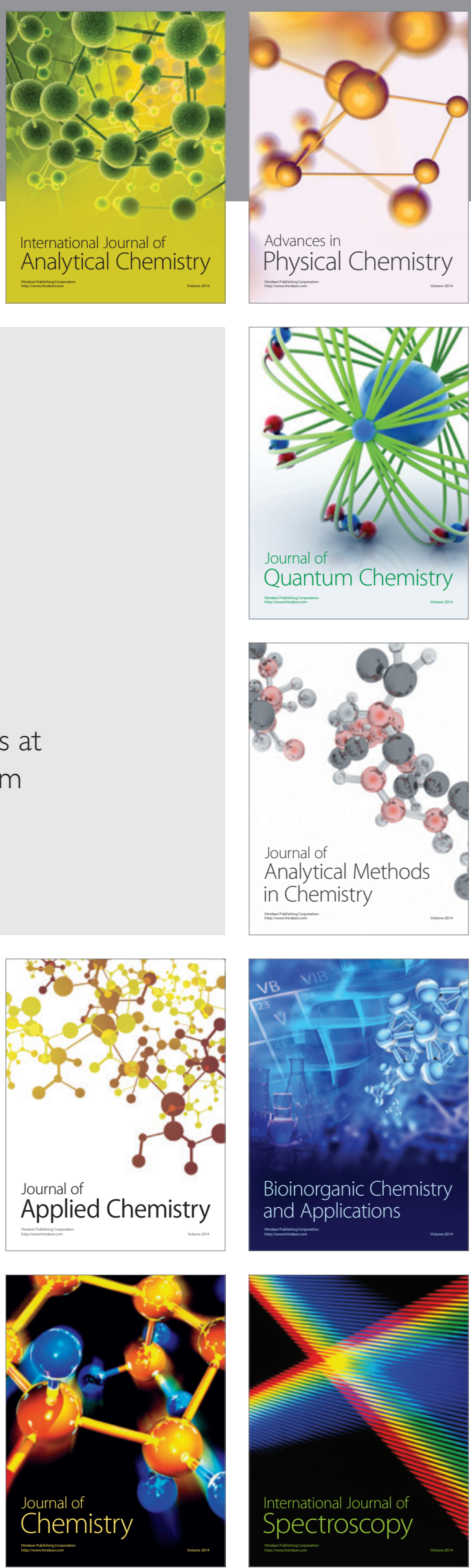